\title{
A MULTIVARIATE LONG-MEMORY MODEL WITH STRUCTURAL BREAKS
}

\author{
Guglielmo Maria Caporale $^{a}$ and Luis A. Gil-Alana ${ }^{b}$

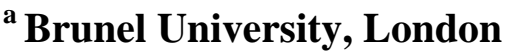 \\ ${ }^{b}$ University of Navarra
}

February 2007

\begin{abstract}
This paper introduces a multivariate long-memory model with structural breaks. In the proposed framework, time series exhibit possibly fractional orders of integration which are allowed to be different in each subsample. The break date is endogenously determined using a procedure which minimises the residual sum of squares (RSS). Monte Carlo experiments show that this method for detecting breaks performs well in large samples. As an illustration, we estimate a trivariate VAR including prices, employment and GDP in both the US and Mexico. For the subsample preceding the break our findings are similar to those of earlier studies based on a standard VAR approach in both countries, in the sense that the variables exhibit integer degrees of integration. On the contrary, the series are found to be fractionally integrated after the break, with the fractional differencing parameters being higher than 1 in the case of Mexico.
\end{abstract}

Keywords: Multivariate models; Fractional integration; Structural breaks.

JEL Classification: $\mathrm{C} 22$

Corresponding author: Professor Guglielmo Maria Caporale, Brunel University, Uxbridge, Middlesex UB8 3PH, UK. Tel.: +44 (0)1895 266713. Fax: +44 (0)1895 269770. Email: Guglielmo-Maria.Caporale@brunel.ac.uk

The second-named author gratefully acknowledges financial support from the Ministerio de Ciencia y Tecnologia (SEJ2005-07657, Spain). 


\section{Introduction}

Mandelbrot (1969) and Mandelbrot and van Ness (1968) found that, although many time series exhibit a persistent trend-cyclical behaviour over a certain time span, when the same data are examined for a longer period, the persistent behaviour tends to disappear. This phenomenon was first noticed in a hydrological context, and called the Hurst effect, in honour of the hydrologist Hurst, (Hurst, 1951, 1957), who, when studying the records on the level of the river Nile, noticed this pattern in its behaviour. In particular, he observed that the autocorrelations took far longer to decay to zero than the exponential rate associated with other classic models such as Auto-Regressive Moving Average (ARMA) ones. This type of process is characterised by long memory, with significant time dependence even between distant observations.

Two alternative definitions of long memory can be provided. Given a discrete covariance stationary time series, $\left\{\mathrm{x}_{\mathrm{t}}, \mathrm{t}=0, \pm 1, \ldots\right\}$, with autocorrelation function $\mathrm{E}\left[\left(\mathrm{x}_{\mathrm{t}}\right.\right.$ - $\left.\left.E x_{t}\right)\left(x_{t-j}-E x_{t}\right)\right]=\gamma_{j}$, according to McLeod and Hipel (1978) the process exhibits long memory if:

$$
\lim _{T \rightarrow \infty} \sum_{j=-T}^{T}\left|\gamma_{j}\right|
$$

is infinite. The second definition is based on the frequency domain. Assuming that $\left\{x_{t}\right\}$ has a continuous spectral distribution, so that it has a spectral density function $f(\lambda)$, one can say that $\left\{\mathrm{x}_{\mathrm{t}}\right\}$ displays the property of long memory if $\mathrm{f}(\lambda)$ has a pole at some frequency $\lambda_{0}$ in the interval $[0, \pi)$. A model with the above features is the Fractional Gaussian Noise one, analysed in Mandelbrot and van Ness (1968). Another simple model, very popular among time series analysts, is the fractionally integrated or I(d) one, where the number of differences required to obtain $\mathrm{I}(0)$ stationarity is not necessarily an integer, but might be instead any real value. Accordingly, one can define $\left\{\mathrm{x}_{\mathrm{t}}\right\}$ as an $\mathrm{I}(\mathrm{d})$ process if: 


$$
(1-L)^{d} x_{t}=u_{t}, \quad t=1,2, \ldots
$$

where $\mathrm{L}$ is the lag-operator (i.e., $\left.\mathrm{L} \mathrm{x}_{\mathrm{t}}=\mathrm{x}_{\mathrm{t}-1}\right)$; $\mathrm{d}$ can be any real value, and $\mathrm{u}_{\mathrm{t}}$ is $\mathrm{I}(0)$, defined as a covariance-stationary process with spectral density function that is positive and finite at any frequency. Note that the fractional differencing polynomial in (1) can be expressed in terms of its Binomial expansion, such that, for all real d,

$$
(1-L)^{d}=\sum_{j=0}^{\infty} \psi_{j} L^{j}=\sum_{j=0}^{\infty}\left(\begin{array}{l}
d \\
j
\end{array}\right)(-1)^{j} L^{j}=1-d L+\frac{d(d-1)}{2} L^{2}-\ldots,
$$

and therefore

$$
(1-L)^{d} x_{t}=x_{t}-d x_{t-1}+\frac{d(d-1)}{2} x_{t-2}-\ldots,
$$

implying that the higher the parameter $\mathrm{d}$ is, the higher the level of association will be between the observations. These processes were introduced by Granger $(1980,1981)$, Granger and Joyeux (1980) and Hosking (1981), and they were theoretically justified in terms of aggregation of autoregressive (AR) processes with random heterogeneous coefficients by Robinson (1978) and Granger (1980). Parke (1999) justifies fractional integration with an error duration model, while Diebold and Inoue (2001) relates fractional integration with regime-switching models (see Baillie, 1996, for an extensive review of $\mathrm{I}(\mathrm{d})$ processes $)^{1}$

Most of the literature on the estimation and testing of I(d) models focuses on the univariate case. Parametric methods can be found in Fox and Taqqu (1986), Dahlhaus (1989), Sowell (1992b), Robinson (1994), etc. Semiparametric approaches are followed by Geweke and Porter-Hudak (1983), Robinson (1995), Velasco (1999), Shimotsu and Phillips (2005), etc. By contrast, the literature on multivariate models is rather limited:

\footnotetext{
${ }^{1}$ Empirical applications of fractional integration to macro series can be found in Diebold and Rudebusch (1989), Sowell (1992a) and Gil-Alana and Robinson (1997) among others.
} 
Gil-Alana $(2003 a, b)$ extends the univariate tests of Robinson (1994) in the frequency domain, while Nielsen (2005) proposes similar tests in the time domain.

In this paper we add to the multivariate literature by proposing a multivariate procedure for estimating the fractional differencing parameters in the presence of structural breaks. For simplicity we focus on the case of a single break, though the analysis can be easily extended to multiple breaks. More specifically, our contribution is twofold. Firstly, we consider a more general (fractional) VAR model, which includes as a special case the standard VAR specification when the orders of integration are equal to 0 or 1 . Secondly, we allow for endogenously determined breaks. The layout of the paper is as follows. Section 2 describes the statistical model and outlines the parameter estimation procedure. Section 3 contains the Monte Carlo simulation results. An empirical application is carried out in Section 4, while Section 5 concludes the paper.

\section{The statistical model}

We start by analysing the case of a single break. Specifically, we consider a model of the form:

$$
\begin{aligned}
& \mathrm{D}^{\mathrm{a}} \mathrm{y}_{\mathrm{t}}=\mathrm{u}_{\mathrm{t}}, \quad \mathrm{t}=1,2, \ldots, \mathrm{T}_{\mathrm{b}}, \\
& \mathrm{D}^{\mathrm{b}} \mathrm{y}_{\mathrm{t}}=\mathrm{u}_{\mathrm{t}}, \quad \mathrm{t}=\mathrm{T}_{\mathrm{b}}+1, \ldots, \mathrm{T},
\end{aligned}
$$

where $y_{t}$ is the $(n x 1)$ vector of observed data; $u_{t}$ is a $(n x 1)$ vector of $I(0)$ processes ${ }^{2} ; D^{a}$ and $\mathrm{D}^{\mathrm{b}}$ are $(\mathrm{nxn})$ diagonal matrices with $\mathrm{i}^{\text {th }}$ elements $(1-L)^{d_{i}^{a}}$ and $(1-L)^{d_{i}^{b}}$ respectively; $\mathrm{T}_{\mathrm{b}}$ is the break date. The procedure minimises the residual sum of squares for a grid of values of the fractional differencing parameters $d_{i}^{a}$ and $d_{j}^{b}, \mathrm{i}, \mathrm{j}=1$, $\ldots, n$. Thus, for a given partition, $\mathrm{T}_{\mathrm{b}}$, and given initial values of the fractional

\footnotetext{
${ }^{2} \mathrm{An} \mathrm{I}(0)$ vector process is defined as a covariance stationary process with spectral density matrix that is finite and positive definite.
} 
differencing parameters $d_{o}^{a}=\left(\mathrm{d}_{10}^{\mathrm{a}}, \mathrm{d}_{20}^{\mathrm{a}}, \ldots, \mathrm{d}_{\text {no }}^{\mathrm{a}}\right)^{\mathrm{T}} ; d_{o}^{b}=\left(\mathrm{d}_{10}^{\mathrm{b}}, \mathrm{d}_{20}^{\mathrm{b}}, \ldots, \mathrm{d}_{\text {no }}^{\mathrm{b}}\right)^{\mathrm{T}}$, the objective function is $\operatorname{RSS}\left(\mathrm{T}_{\mathrm{b}} ; \mathrm{d}_{\mathrm{o}}^{\mathrm{a}}, \mathrm{d}_{\mathrm{o}}^{\mathrm{b}}\right)$, and minimising this expression for all values of $d_{o}^{a}$ and $d_{o}^{b}$, one obtains:

$$
\operatorname{RSS}\left(\mathrm{T}_{\mathrm{b}}\right)=\arg \min _{\{\mathrm{k}\}} \operatorname{RSS}\left(\mathrm{T}_{\mathrm{b}} ; \mathrm{d}_{\mathrm{ik}}^{\mathrm{a}}, \mathrm{d}_{\mathrm{jk}}^{\mathrm{b}}\right), \quad \mathrm{i}, \mathrm{j}=1,2, \ldots, \mathrm{n} .
$$

Then, the estimated break date, $\hat{\mathrm{T}}_{\mathrm{k}}$, is such that

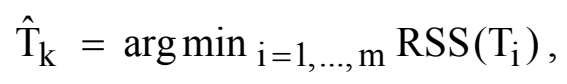

where the minimisation is done over all partitions $T_{1}, T_{2}, \ldots, T_{m}$, such that $T_{i}-T_{i-1} \geq$ $|\varepsilon T|$. Hence, the estimated fractionally differencing parameters associated to the estimated k-partition are:

$$
\left.\left.\hat{\mathrm{d}}_{\mathrm{i}}^{\mathrm{a}}=\hat{\mathrm{d}}_{\mathrm{i}}^{\mathrm{a}}\left\{\hat{\mathrm{T}}_{\mathrm{k}}\right\}\right) \text { and } \hat{\mathrm{d}}_{\mathrm{j}}^{\mathrm{b}}=\hat{\mathrm{d}}_{\mathrm{j}}^{\mathrm{b}}\left\{\hat{\mathrm{T}}_{\mathrm{k}}\right\}\right)
$$

for $\mathrm{i}, \mathrm{j}=1,2, \ldots \mathrm{n}$.

Clearly, the model can be extended to the case of multiple breaks by considering the following specification:

$$
\mathrm{D}^{\mathrm{j}} \mathrm{y}_{\mathrm{t}}=\mathrm{u}_{\mathrm{t}}, \quad \mathrm{t}=\mathrm{T}_{\mathrm{j}-1}+1, \ldots, \mathrm{T}_{\mathrm{j}}
$$

for $\mathrm{j}=1, \ldots, \mathrm{m}+1, \mathrm{~T}_{0}=0$ and $\mathrm{T}_{\mathrm{m}+1}=\mathrm{T}$, with the parameter $\mathrm{m}$ representing the number of breaks. The break dates $\left(\mathrm{T}_{1}, \ldots, \mathrm{T}_{\mathrm{m}}\right)$ are treated as unknown and for $\mathrm{i}=1, \ldots, \mathrm{m}$, we have $\lambda_{\mathrm{i}}=\mathrm{T}_{\mathrm{i}} / \mathrm{T}$, with $\lambda_{1}<\ldots<\lambda_{\mathrm{m}}<1$. Following the same approach as in the previous case, for each $\mathrm{j}$-partition, $\left\{\mathrm{T}_{1}, \ldots \mathrm{T}_{\mathrm{j}}\right\}$, denoted $\left\{\mathrm{T}_{\mathrm{j}}\right\}$, the estimates of the $\mathrm{d}^{\mathrm{j}} \mathrm{s}$ are obtained by minimising the sum of squared residuals in the d-differenced models, i.e.,

$$
\sum_{j=1}^{m+1} \sum_{t=T}^{T}\left(D_{j-1}^{j} y_{t}\right)^{T}\left(D^{j} y_{t}\right)
$$


where $\hat{d}\left(T_{j}\right)$ denotes the resulting estimates. Substituting into the new objective function and denoting the sum of squared residuals as $\operatorname{RSS}_{\mathrm{T}}\left(\mathrm{T}_{1}, \ldots, \mathrm{T}_{\mathrm{m}}\right)$, the estimated break dates $\left(\hat{T}_{1}, \hat{T}_{2}, \ldots, \hat{T}_{m}\right)$ are obtained as follows

$$
\min \left(\mathrm{T}_{1}, \mathrm{~T}_{2}, \ldots, \mathrm{T}_{\mathrm{m}}\right) \operatorname{RSS}_{\mathrm{T}}\left(\mathrm{T}_{1}, \ldots, \mathrm{T}_{\mathrm{m}}\right)
$$

where the minimisation is again obtained over all partitions $\left(\mathrm{T}_{1}, \ldots, \mathrm{T}_{\mathrm{m}}\right)$.

\section{A Monte Carlo simulation study}

The data generating process is a trivariate model given by:

$$
\begin{aligned}
& \left(\begin{array}{ccc}
(1-\mathrm{L})^{\mathrm{d}_{1}^{\mathrm{a}}} & 0 & 0 \\
0 & (1-\mathrm{L})^{\mathrm{d}_{2}^{\mathrm{a}}} & 0 \\
0 & 0 & (1-\mathrm{L})^{\mathrm{d}_{3}^{\mathrm{a}}}
\end{array}\right)\left(\begin{array}{l}
\mathrm{y}_{1, \mathrm{t}} \\
\mathrm{y}_{2, \mathrm{t}} \\
\mathrm{y}_{3, \mathrm{t}}
\end{array}\right)=\left(\begin{array}{l}
\mathrm{u}_{1, \mathrm{t}} \\
\mathrm{u}_{2, \mathrm{t}} \\
\mathrm{u}_{3, \mathrm{t}}
\end{array}\right), \quad \mathrm{t}=1,2, \ldots, \mathrm{T}_{\mathrm{b}}, \\
& \left(\begin{array}{ccc}
(1-\mathrm{L})^{\mathrm{d}_{1}^{\mathrm{b}}} & 0 & 0 \\
0 & (1-\mathrm{L})^{\mathrm{d}_{2}^{\mathrm{b}}} & 0 \\
0 & 0 & (1-\mathrm{L})^{\mathrm{d}_{3}^{\mathrm{b}}}
\end{array}\right)\left(\begin{array}{l}
\mathrm{y}_{1, \mathrm{t}} \\
\mathrm{y}_{2, \mathrm{t}} \\
\mathrm{y}_{3, \mathrm{t}}
\end{array}\right)=\left(\begin{array}{l}
\mathrm{u}_{1, \mathrm{t}} \\
\mathrm{u}_{2, \mathrm{t}} \\
\mathrm{u}_{3, \mathrm{t}}
\end{array}\right), \quad \mathrm{t}=\mathrm{T}_{\mathrm{b}}+1, \ldots, \mathrm{T},
\end{aligned}
$$

with white noise $u_{\mathrm{t}}$, and initially (in Table 1) we assume that $d_{1}^{a}=0.2 ; d_{2}^{a}=0.4$; $d_{3}^{a}=0.3$, while $d_{1}^{b}=0.6 ; d_{2}^{b}=0.9$ and $d_{3}^{b}=1.4$. Thus, the orders of integration are higher in the second subsample for the three series, which are stationary before the break, occurring at $T_{b}=T / 2$, and nonstationary afterwards. To conduct this experiment, we generate Gaussian series using the routines GASDEV and RAN3 of Press, Flannery, Teukolsky and Wetterling (1986), with sample sizes $\mathrm{T}=100,200,300,500$ and 1000. The number of replications is 1000 in each case.

We followed the procedure described in Section 2 for a grid of values of the d's from 0 to 2 with 0.2 increments and estimated break dates $\mathrm{T}^{*}=\mathrm{T} / 10, \mathrm{~T} / 10+1, \ldots$, 
9T/10 - 1 and 9T/10. Table 1 reports the percentage of cases corresponding to the minimum RSS. In order to save space we only display cases with a probability higher than 0.01 .

It can be seen that all such probabilities correspond to the values $\mathrm{T}^{*}=\mathrm{T} / 2-2$, $\mathrm{T} / 2-1, \mathrm{~T} / 2, \mathrm{~T} / 2+1$ and $\mathrm{T} / 2+2$, the highest probability mass being concentrated around the true break date $\mathrm{T} / 2$. If $\mathrm{T}=100$, the probability of correctly determining the break date along with the six fractional differencing parameters is very small $(0.031)$, though it is the highest of all cases. This indicates that, for this small size, the probabilities are spread widely across all cases. When increasing the sample size, the probabilities corresponding to the true cases substantially increase, being equal to $14.6 \%$ with $\mathrm{T}=200 ; 33.8 \%$ with $\mathrm{T}=300 ; 77.6 \%$ if $\mathrm{T}=500$ and higher than $90 \%$ with $\mathrm{T}=1000$

\section{INSERT TABLES 1 - 3 ABOUT HERE}

Table 2 displays similar results for a model with $\mathrm{d}^{\mathrm{a}}=[0.8,1.2,0.6]^{\mathrm{T}}$ and $\mathrm{d}^{\mathrm{b}}=$ $[0.2,0.4,0.2]^{\mathrm{T}}$ and the break occurring at $\mathrm{T} / 4$. The probabilities of correctly determining the break date along with the fractional differencing parameters are slightly smaller than before, though again increasing with the sample size. However, the probability mass around the true break is now higher: even for a sample size of $\mathrm{T}=100$ the percentage around $\mathrm{T} / 4$ is 0.750 .

In Table 3 we combine stationary and nonstationary processes for each subsample, $\mathrm{d}^{\mathrm{a}}=[0.6,0.3,0.5]^{\mathrm{T}}, \mathrm{d}^{\mathrm{b}}=[0.2,0.9,0.5]^{\mathrm{T}}$ and $\mathrm{T}^{\mathrm{b}}=3 \mathrm{~T} / 4$. The results are similar to those presented in Table 2, with the highest probabilities corresponding to the true model in all cases, and increasing with $\mathrm{T}$. 
In Table 4 we extend the model to allow for weak parametric autocorrelation, and consider the model in (4) and (5) with $\mathrm{d}^{\mathrm{a}}=[0.2,0.4,0.3]^{\mathrm{T}}$, and $\mathrm{d}^{\mathrm{b}}=[0.6,0.9,1.4]^{\mathrm{T}}$, $\mathrm{T}^{\mathrm{b}}=\mathrm{T} / 2$, and $\mathrm{u}_{\mathrm{t}}$ following a VAR(1) process of the form:

$$
\begin{aligned}
& \left(\begin{array}{l}
u_{1, t} \\
u_{2, t} \\
u_{3, t}
\end{array}\right)=\left(\begin{array}{lll}
0.2 & 0.1 & 0.6 \\
0.2 & 0.3 & 0.1 \\
0.1 & 0.2 & 0.2
\end{array}\right)\left(\begin{array}{l}
u_{1, t-1} \\
u_{2, t-1} \\
u_{3, t-1}
\end{array}\right)+\left(\begin{array}{l}
\varepsilon_{1, t} \\
\varepsilon_{2, t} \\
\varepsilon_{3, t}
\end{array}\right), \quad t=1,2, \ldots, T_{b} \\
& \left(\begin{array}{l}
u_{1, t} \\
u_{2, t} \\
u_{3, t}
\end{array}\right)=\left(\begin{array}{lll}
0.6 & 0.1 & 0.3 \\
0.4 & 0.5 & 0.5 \\
0.1 & 0.1 & 0.5
\end{array}\right)\left(\begin{array}{l}
u_{1, t-1} \\
u_{2, t-1} \\
u_{3, t-1}
\end{array}\right)+\left(\begin{array}{l}
\varepsilon_{1, t} \\
\varepsilon_{2, t} \\
\varepsilon_{3, t}
\end{array}\right), \quad t=T_{b}+1, \ldots, T,
\end{aligned}
$$

with white noise $\varepsilon_{\mathrm{t}}$.

\section{INSERT TABLE 4 ABOUT HERE}

It is apparent that in this case, if the sample size is small $(\mathrm{T}=100)$, the probability of correctly determining the break date and the fractional differencing parameters is negligible (smaller than 0.01 ), though the probability mass around the true break date is $44.8 \%$. If $\mathrm{T}=200$ the probability around the true values is still small (5.2\%), though it is the highest of all. As in the previous cases, when increasing $\mathrm{T}$, the probabilities around the true values also increase, and, if $\mathrm{T}=1000$, the true probability is around $75.7 \%$, while the probabilities for the remaining cases never exceed $5 \%$.

\section{An empirical application}

In this section we apply the procedure outlined above to analyse the linkages between prices (inflation), employment and GDP in the US and Mexico in a fractional multivariate model allowing for a single, endogenously determined break. We choose 
these two countries as representative of the G-7 and emerging economies respectively, and as they most likely exhibit breaks at different points in time.

Two types of models are estimated in the existing literature. The first is the standard VAR, namely,

$$
\begin{gathered}
D(L) y_{t}^{*}=u_{t}, \quad t=1,2, \ldots, \\
y_{t}^{*}=\left(\begin{array}{c}
* \\
y_{1, t}^{*} \\
y_{2, t}^{*} \\
* \\
y_{3, t}
\end{array}\right)=\left(\begin{array}{l}
(1-L)^{d_{1}} y_{1, t} \\
(1-L)^{d_{2}} y_{2, t} \\
(1-L)^{d_{3}} y_{3, t}
\end{array}\right), \quad t=1,2, \ldots,
\end{gathered}
$$

where integer degrees of differentiation $d_{1}, d_{2}$ and $d_{3}$ are implicitly assumed. In other words, the series are individually pre-tested using classical methods (Dickey and Fuller, 1979; Phillips and Perron, 1988; etc.) to determine if they should be included in (6) in levels $(d=0)$ or in first differences $(d=1)$ (Sims, 1980). Examples of this type of analysis are the papers of Debenedictis (1997), Aucremanne and Wouters (1999), Claus (2000), Canova (2002), etc.

The second approach is based on cointegration, assuming that there are some common trends implying $\mathrm{I}(0)$ equilibrium relationships between the variables (Johansen, 1988, 1991). Here the implicit assumption is again that at least two of the series are nonstationary I(1). Papers along these lines include those of Cameron, Hum and Simpson (1996), Pétursson and Slok (2001) and Reade (2005). The present study falls within the first category, since it is a generalisation of the VAR model to the fractional VAR case including a structural break as well.

\subsection{The US case}

The series analysed in this subsection are the Consumer Price Index (for all urban consumers, all items), and civilian employment (sixteen years and over), both obtained 
from the U.S. Department of Labor (Bureau of Labour Statistics), and GDP, provided by the U.S. Department of Commerce (Bureau of Economic Analysis), all quarterly, seasonally adjusted, for the time period 1948q1 2006q2. All series in the estimated model are in logs.

\section{INSERT TABLE 5 ABOUT HERE}

We perform the procedure described in Section 2 for values of $\left(d^{a}, d^{b}\right)$ in $(4)$ and (5) in the interval -2 to 2 , with 0.01 increments, and estimated break date $T^{*}=T / 10$, $\mathrm{T} / 10+1, \ldots, 9 \mathrm{~T} / 10-1,9 \mathrm{~T} / 10 .^{3}$ Table 5 reports the results based on white noise disturbances. It can be seen that the break takes place at 1974Q4 (1975Q1), which corresponds to the first OPEC oil price shock. In the first subsample the order of integration of the three series is 1 or close to 1 - more precisely, the order of integration of CPI and GDP ( $d_{2}$ and $d_{3}$ respectively) is exactly equal to 1 , whilst it is 1.01 for employment $\left(\mathrm{d}_{1}\right)$. However, after the break, the three orders of integration are much higher than 1, ranging from 1.45 (CPI) to 1.52 (GDP). Therefore, there is a substantial increase in the degree of persistence of the three series after the break. Confidence intervals for the estimated fractional differencing parameters can be obtained using boostrapping methods, although they are highly computationally expensive. Instead, we have computed Gil-Alana's $(2003 a, b)$ multivariate version of the univariate tests of Robinson (1994) for each subsample, which enables us to obtain confidence intervals for the fractional differencing parameters. The 95\% confidence intervals are also displayed in Table 5. As expected, the unit root null hypothesis cannot be rejected for

\footnotetext{
${ }^{3}$ Following standard practice, we have not considered $10 \%$ of the observations at both ends of the sample.
} 
any of the three series in the first subsample, though this hypothesis is decisively rejected after the break.

\section{INSERT TABLE 6 ABOUT HERE}

Table 6 shows the results with VAR (1) disturbances. The break again occurs at 1974Q4 (1975Q1), but now in the first subsample the three orders of integration are 0 or close to 0 and the null hypothesis of $\mathrm{I}(0)$ cannot be rejected for any series. This is clearly because the time dependence is now captured by the VAR coefficients, which are close to 1 in all cases. After the break, the values of the d parameters range between 0 and 1 , and the two $\mathrm{I}(0)$ and $\mathrm{I}(1)$ hypotheses are rejected in the cases of employment and GDP. Specifically, the values are 0.66 for employment; 0.25 for CPI and 0.43 for GDP. Therefore, in both cases (whether with white noise or autocorrelated disturbances), we observe an increase in the degree of persistence after the break in 1975.

\subsection{The Mexican case}

We analyse the same variables also for Mexico, more specifically consumer price index $(1970=100)$, economically active population (EAP, in thousand values), and GDP (million 1970 PPP\$), annually, from 1900 to 2000. The data are taken from the Oxford Latin American Economic History Database, Latin American Centre at Oxford University (http://oxlad.qeh.ox.ac.uk). Similarly to the US case, the series are logtransformed.

Tables 7 and 8 are similar to Tables 5 and 6 above but refer to the Mexican case, that is, they correspond to the estimated multivariate fractional models with a single 
break for the two cases of white noise and VAR(1) disturbances respectively. It can be seen that, if $\mathrm{u}_{\mathrm{t}}$ is specified as a white noise, the break occurs in 1959, whilst the break date is 1962 with autocorrelated disturbances.

\section{INSERT TABLES 7 AND 8 ABOUT HERE}

The results based on white noise disturbances are very similar to the US ones. Before the break, the orders of integration are close to 1 for the three series: 1.06 for prices, 0.97 for employment, and 0.99 for GDP and the unit root cannot be rejected for any of the series. However, after the break, they are significantly above 1, ranging from 1.37 (GDP) to 1.77 (employment), and the unit root null hypothesis is rejected for the three series. If a VAR(1) structure is incorporated into the model, they are around 0 before the break, once more reflecting the competition with the VAR parameters in capturing nonstationarity, while, after the break, the corresponding values are strictly above 1 for all three series considered. ${ }^{4}$

Overall, in the subsample before the break, the results for the three series in the two countries are consistent with the standard approach employed in the literature, that is, the series are found to be either I(1) (if no autocorrelation is allowed for) or I(0) (when modelling the disturbances as VAR(1) processes). However, after the breaks, the series are clearly fractionally integrated: for the US, the values range between 1 and 2 without autocorrelation in the disturbances, and lie between 0 and 1 with autocorrelated $\mathrm{u}_{\mathrm{t}}$. In Mexico, though, regardless of whether or not autocorrelation is allowed for, the series are in all cases $\mathrm{I}(\mathrm{d})$ with d lying between 1 and 2.

\footnotetext{
${ }^{4}$ Note, however, that the null hypothesis of a unit root cannot be rejected for any of the series in the second subsample.
} 
This paper introduces a multivariate long-memory model with structural breaks. In the proposed framework, time series exhibit possibly fractional orders of integration which are allowed to be different in each subsample. The break point is endogenously determined using a procedure which minimises the residual sum of squares (RSS). Monte Carlo experiments show that this method for detecting the break performs well in large samples. Both the multivariate fractional nature of the suggested model, and the endogenous determination of breaks represent innovative features of the present study compared to earlier ones, which are based on standard VAR models with or without structural breaks (e.g., McConnell and Perez-Quiros, 2000; Chauvet and Potter, 2001; Kim, Nelson and Piger, 2001, etc.)

As an illustration, we apply our procedure to estimate a trivariate VAR including prices, employment and GDP both in the US and Mexico. For the subsample preceding the break our findings are similar to those of earlier studies based on a standard VAR approach in both countries, in the sense that the variables exhibit integer degrees of integration. On the contrary, the series are found to be fractionally integrated after the break, with the fractional differencing parameters being higher than 1 for the three series in the case of Mexico.

The present study can be extended in several ways. First, deterministic components like intercepts, linear trends or even non-linear structures (Caporale and Gil-Alana, 2007) can be included in the regression models, therefore allowing for fractionally integrated regression errors. Moreover, allowance can be made for multiple breaks, though, given the long memory characteristic of the processes analysed here, a long span of data would be required. Finally, the fractional polynomials used in the model specification adopted in this paper imply the existence of a pole or singularity in 
the spectral density function at the zero frequency - this can clearly be generalised to the case of a pole at a frequency other than zero for some or all series considered. This could also lead to the analysis of seasonal multivariate fractional models, which to date have not been extensively investigated. 


\section{References}

Aucremanne, L. and R. Wouters, 1999, A structural VAR approach to core inflation and its relevance for monetary policy, in BIS (eds.), Measures of Underlying Inflation and their Role in the Conduct ofMonetary Policy, Proceedings of the Workshop of Central Bank Model Builders, Amsterdam.

Baillie, R.T., 1996, Long memory processes and fractional integration in econometrics. Journal of Econometrics 73, 5-59.

Cameron, N., D. Hum and W. Simpson, 1996, Stylized facts and stylized illusions: inflation and productivity revisited, Canadian Journal of Economics 29, 152-162.

Canova, F., 2002, G7 Inflation forecasts, ECB Working Paper No. 151.

Chauvet, M. and S. Potter, 2001, Recent changes in the US business cycle, Federal Reserve Bank of New York, Staff Reports, n. 126.

Caporale, G.M. and L.A. Gil-Alana, 2007, Non-linearities and fractional integration in the US unemployment rate, Oxford Bulletin of Economics and Statistics, forthcoming. Claus, I., 2000, Estimating potential output for New Zeeland. A structural VAR approach, Reserve Bank of New Zeeland, Discussion Paper 2000/03.

Dahlhaus, R., 1989, Efficient parameter estimation for self similar processes, Annals of Statistics 17, 1749-1766.

Debenedictis, L.F., 1997, A vector autoregressive model of the British Columbia regional economy, Applied Economics 29, 877-888.

Dickey, D. and W. Fuller, 1979, Distribution of the estimators for autoregressive time series with a unit root, Journal of the American Statistical Association, 74, 427-431.

Diebold, F.X. and A. Inoue, 2001, Long memory and regime switching, Journal of Econometrics 105, 131-159. 
Diebold, F.X. and G.D. Rudebusch, 1989, Long memory and persistence in aggregate output, Journal of Monetary Economics 24, 189-209.

Fox, R. and M.S. Taqqu, 1986, Large sample properties of parameter estiamtes for strongly dependent stationary Gaussian time series, Annals of Statistics 14, 517-532.

Geweke, J. and S. Porter-Hudak, 1983, The estimation and application of long memory time series models, Journal of Time Series Analysis 4, 221-238.

Gil-Alana, L.A., 2003a, Multivariate tests of nonstationary hypotheses, South African Statistical Journal 37, 1-28.

Gil-Alana, L.A., 2003b, A fractional multivariate long memory model for the US and the Canadian real output, Economics Letters 81, 355-359.

Gil-Alana, L.A. and P.M. Robinson, 1997, Testing of unit roots and other nonstationary hypotheses in macroeconomic time series, Journal of Econometrics 80, 241-268.

Granger, C.W.J., 1980, Long memory relationships and the aggregation of dynamic models, Journal of Econometrics 14, 227-238.

Granger, C.W.J., 1981, Some properties of time series data and their use in econometric model specification, Journal of Econometrics 16, 121-130.

Granger, C.W.J. and R. Joyeux, 1980, An introduction to long memory time series and fractional differencing, Journal of Time Series Analysis 1, 15-29.

Hosking, J.R.M., 1981, Fractional differencing, Biometrika 68, 165-176.

Hurst, H.E., 1951, Long term storage capacity of reservoirs, Transactions of the American Society Civil Engineering 116, 770-779.

Hurst, H.E., 1957, A suggested statistical model of some time seris which occur in nature, Nature 180, 494.

Johansen, S., 1988, Statistical analysis of cointegration vectors, Journal of Economic Dynamics and Control, 12, 231-254 
Johansen, S., 1991, Estimation and hypothesis testing of cointegration vectors in Gaussian vector autoregressive models, Econometrica, 59, 1551-1580.

Kim, C., C. Nelson and J. Piger, 2001, The less volatile US economy. A Bayesian investigation of breadth and potential explanations, Unpublished paper, Board of Governors of the Federal Reserve System.

Mandelbrot, B., 1969, Long run linearity, locally Gaussian processes, H-spectra and infinite variances, International Economic Review 75, 828-835.

Mandelbrot, B. and J.W. van Ness, 1968, Fractional Brownian motions, fractional noises and applications, SIAM Review 10, 422-437.

McConnel, M.M. and G. Perez-Quiros, 2000, Output fluctuations in the United States. What has changed since the early 1980s, American Economic Review 90, 1464-1476.

McLeod, A.I. and K.W. Hipel, 1978, Preservation of the rescaled adjusted range. A reassessment of the Hurst phenomenon, Waer Resources Research 14, 491-507.

Nielsen, M.O., 2005, Efficient inference in multivariate fractionally integrated time series models, Econometric Journal, Royal Economic Society 7, 63-97.

Parke, W.R., 1999, What is fractional integration?, Review of Economics and Statistics $81,632-638$.

Pétursson, T.G. and T. Slok, 2001, Wage formation and employment in a cointegrated VAR model, The Econometrics Journal 4, 191-209.

Phillips, P.C.B. and P. Perron, 1988, Testing for a unit root in a time series regression, Biometrika, 75, 335-346.

Press, W.H., B.P. Flannery, S.A. Teukolsky and W.T. Wetterling, 1986, Numerical recipes: The Art of Scientific Computing, Cambridge University Press, Cambridge. Reade, J., 2005, A cointegrated VAR analysis of employemnt, Project for Econometrics Summer School in Copenhaguen. 
Robinson, P.M., 1978, Statistical inference for a random coefficient autoregressive model, Scandinavian Journal of Statistics 5, 163-168.

Robinson, P.M., 1994, Efficient tests of nonstationary hypotheses, Journal of the American Statistical Association 89, 1420-1437.

Robinson, P.M., 1995, Gaussian semiparametric estimation of long range dependence, Annals of Statistics 23, 1630-1661.

Shimotsu, K. and P.C.B. Phillips, 2005, Exact local Whittle estimation of fractional integration, Annals of Statistics 33, 1890-1933.

Sims, C., 1980, Macroeconomics and reality, Econometrica 48, 1- 48.

Sowell, F., 1992a, Modelling long run behaviour with the fractional ARIMA model, Journal of Monetary Economics 29, 277-302.

Sowell, F., 1992b, Maximum likelihood estimation of stationary univariate fractionally integrated time series models, Journal of Econometrics 53, 165-188.

Velasco, C., 1999, Gaussian semiparametric estimation of nonstationary time series, Journal of Econometrics 20, 87-127. 
TABLE 1

Probabilities of detecting the true break date in a model with $T_{b}=T / 2$ and $d^{a}=[0.2,0.4$, $0.3]^{\mathrm{T}}$ and $\mathrm{d}^{\mathrm{b}}=[0.6,0.9,1.4]^{\mathrm{T}}$

\begin{tabular}{|c|c|c|c|c|c|c|c|c|c|c|c|}
\hline \multicolumn{4}{|c|}{ First subsample } & \multicolumn{3}{|c|}{ Second subsample } & \multicolumn{5}{|c|}{ Sample size } \\
\hline$T / 2$ & $\mathrm{~d}_{1}$ & $\mathrm{~d}_{2}$ & $\mathrm{~d}_{3}$ & $\mathrm{~d}_{1}$ & $\mathrm{~d}_{2}$ & $\mathrm{~d}_{3}$ & 100 & 200 & 300 & 500 & 1000 \\
\hline $\mathrm{T} / 2-2$ & 0.2 & 0.4 & 0.3 & 0.6 & 0.9 & 1.4 & ----- & 0.014 & 0.026 & 0.018 & 0.003 \\
\hline \multirow{2}{*}{$\mathrm{T} / 2-1$} & 0.2 & 0.4 & 0.1 & 0.6 & 0.9 & 1.4 & ----- & ----- & 0.010 & ---- & ---- \\
\hline & 0.2 & 0.4 & 0.3 & 0.6 & 0.9 & 1.4 & 0.010 & 0.031 & 0.052 & 0.036 & 0.022 \\
\hline \multirow{14}{*}{$\mathrm{T} / 2$} & 0.0 & 0.4 & 0.3 & 0.6 & 0.9 & 1.4 & 0.016 & 0.017 & 0.035 & 0.013 & ---- \\
\hline & 0.2 & 0.2 & 0.1 & 0.6 & 0.9 & 1.4 & ----- & 0.010 & $\begin{array}{ll}---- \\
\end{array}$ & ----- & $\begin{array}{l}----- \\
\end{array}$ \\
\hline & 0.2 & 0.2 & 0.3 & 0.6 & 0.9 & 1.4 & 0.014 & 0.029 & 0.021 & 0.016 & ---- \\
\hline & 0.2 & 0.4 & 0.1 & 0.6 & 0.9 & 1.4 & 0.014 & 0.017 & 0.020 & 0.007 & ----- \\
\hline & 0.2 & 0.4 & 0.3 & 0.4 & 0.9 & 1.4 & 0.011 & 0.024 & 0.017 & 0.006 & ---- \\
\hline & 0.2 & 0.4 & 0.3 & 0.6 & 0.7 & 1.4 & 0.016 & 0.020 & 0.016 & 0.011 & ----- \\
\hline & 0.2 & 0.4 & 0.3 & 0.6 & 0.9 & 1.2 & 0.011 & 0.019 & 0.030 & 0.011 & ----- \\
\hline & 0.2 & 0.4 & 0.3 & 0.6 & 0.9 & 1.4 & 0.031 & 0.146 & 0.338 & 0.776 & 0.913 \\
\hline & 0.2 & 0.4 & 0.3 & 0.6 & 0.9 & 1.6 & ----- & 0.025 & 0.020 & ----- & ----- \\
\hline & 0.2 & 0.4 & 0.3 & 0.6 & 1.1 & 1.4 & 0.012 & 0.017 & 0.013 & 0.013 & ----- \\
\hline & 0.2 & 0.4 & 0.3 & 0.8 & 0.9 & 1.4 & ----- & 0.014 & 0.019 & 0.013 & ----- \\
\hline & 0.2 & 0.4 & 0.5 & 0.6 & 0.9 & 1.4 & ----- & 0.026 & 0.019 & 0.011 & ----- \\
\hline & 0.2 & 0.6 & 0.3 & 0.6 & 0.9 & 1.4 & 0.012 & 0.017 & 0.014 & 0.003 & ----- \\
\hline & 0.4 & 0.4 & 0.3 & 0.6 & 0.9 & 1.4 & ----- & 0.021 & 0.014 & ----- & ----- \\
\hline $\mathrm{T} / 2+1$ & 0.2 & 0.4 & 0.3 & 0.6 & 0.9 & 1.4 & ----- & 0.023 & 0.050 & 0.033 & 0.012 \\
\hline $\mathrm{T} / 2+2$ & 0.2 & 0.4 & 0.3 & 0.6 & 0.9 & 1.4 & ----- & 0.015 & 0.040 & 0.033 & 0.009 \\
\hline \multicolumn{7}{|c|}{ Percentage of cases with the break at $\mathrm{T} / 2-2$} & 0.081 & 0.072 & 0.051 & 0.032 & 0.003 \\
\hline \multicolumn{7}{|c|}{ Percentage of cases with the break at $\mathrm{T} / 2-1$} & 0.140 & 0.113 & 0.102 & 0.056 & 0.025 \\
\hline \multicolumn{7}{|c|}{ Percentage of cases with the break at $\mathrm{T} / 2$} & 0.599 & 0.648 & 0.710 & 0.942 & 0.951 \\
\hline \multicolumn{7}{|c|}{ Percentage of cases with the break at $\mathrm{T} / 2+1$} & 0.102 & 0.092 & 0.082 & 0.045 & 0.012 \\
\hline \multicolumn{7}{|c|}{ Percentage of cases with the break at $\mathrm{T} / 2+2$} & 0.079 & 0.075 & 0.055 & 0.015 & 0.009 \\
\hline
\end{tabular}




\section{TABLE 2}

Probabilities of detecting the true break date in a model with $T_{b}=T / 4$ and $d^{a}=[0.8,1.2$, $0.6]^{\mathrm{T}}$ and $\mathrm{d}^{\mathrm{b}}=[0.2,0.4,0.2]^{\mathrm{T}}$

\begin{tabular}{|c|c|c|c|c|c|c|c|c|c|c|c|}
\hline \multicolumn{4}{|c|}{ First subsample } & \multicolumn{3}{|c|}{ Second subsample } & \multicolumn{5}{|c|}{ Sample size } \\
\hline $\mathrm{T} / 4-1$ & $\mathrm{~d}_{1}$ & $\mathrm{~d}_{2}$ & $\mathrm{~d}_{3}$ & $\mathrm{~d}_{1}$ & $\mathrm{~d}_{2}$ & $\mathrm{~d}_{3}$ & 100 & 200 & 300 & 500 & 1000 \\
\hline \multirow{31}{*}{$\mathrm{T} / 4$} & 0.6 & 1.0 & 0.4 & 0.2 & 0.4 & 0.2 & 0.011 & 0.009 & ----- & ----- & ----- \\
\hline & 0.6 & 1.0 & 0.6 & 0.2 & 0.4 & 0.0 & 0.010 & ----- & ----- & ----- & ----- \\
\hline & 0.6 & 1.0 & 0.6 & 0.2 & 0.4 & 0.2 & 0.018 & 0.016 & 0.016 & ----- & ----- \\
\hline & 0.6 & 1.0 & 0.8 & 0.2 & 0.4 & 0.2 & 0.015 & ----- & ----- & ----- & ----- \\
\hline & 0.6 & 1.2 & 0.4 & 0.2 & 0.4 & 0.2 & 0.015 & 0.015 & 0.011 & ------ & ----- \\
\hline & 0.8 & 1.2 & 0.8 & 0.2 & 0.4 & 0.2 & 0.020 & 0.056 & 0.073 & 0.053 & 0.024 \\
\hline & 0.6 & 1.2 & 0.8 & 0.2 & 0.4 & 0.2 & 0.010 & 0.010 & 0.017 & ---- & $\begin{array}{l}----- \\
-\end{array}$ \\
\hline & 0.6 & 1.4 & 0.4 & 0.2 & 0.4 & 0.2 & 0.012 & ---- & ----- & ----- & ----- \\
\hline & 0.6 & 1.4 & 0.6 & 0.2 & 0.4 & 0.2 & ---- & 0.013 & 0.013 & ----- & ----- \\
\hline & 0.8 & 1.4 & 0.8 & 0.2 & 0.4 & 0.2 & 0.010 & ----- & ---- & ---- & ----- \\
\hline & 0.8 & 1.0 & 0.4 & 0.2 & 0.4 & 0.2 & 0.016 & 0.022 & 0.015 & ---- & ----- \\
\hline & 0.8 & 1.0 & 0.6 & 0.2 & 0.4 & 0.2 & 0.018 & 0.053 & 0.064 & 0.061 & 0.025 \\
\hline & 0.8 & 1.0 & 0.8 & 0.2 & 0.4 & 0.2 & 0.015 & 0.017 & 0.011 & ----- & ----- \\
\hline & 0.8 & 1.2 & 0.4 & 0.0 & 0.4 & 0.2 & ----- & 0.010 & ----- & ----- & ----- \\
\hline & 0.8 & 1.2 & 0.4 & 0.2 & 0.4 & 0.2 & 0.021 & 0.060 & 0.077 & 0.054 & 0.026 \\
\hline & 0.8 & 1.2 & 0.6 & 0.0 & 0.4 & 0.2 & 0.010 & 0.012 & 0.013 & ----- & ------ \\
\hline & 0.8 & 1.2 & 0.6 & 0.2 & 0.2 & 0 & ----- & 0.011 & ----- & ----- & ----- \\
\hline & 0.8 & 1.2 & 0.6 & 0.2 & 0.4 & 0.0 & ----- & 0.012 & 0.015 & ----- & ----- \\
\hline & 0.8 & 1.2 & 0.6 & 0.2 & 0.4 & 0.2 & 0.020 & 0.136 & 0.287 & 0.565 & 0.847 \\
\hline & 0.8 & 1.2 & 0.6 & 0.2 & 0.6 & 0.4 & ----- & 0.014 & ----- & ----- & ----- \\
\hline & 0.8 & 1.2 & 0.6 & 0.2 & 0.6 & 0 & ----- & ----- & 0.013 & 0.011 & ----- \\
\hline & 0.8 & 1.2 & 0.6 & 0.4 & 0.4 & 0 & ----- & 0.013 & ----- & ----- & |---- \\
\hline & 0.8 & 1.2 & 0.8 & 0.2 & 0.4 & 0.2 & 0.014 & 0.049 & 0.044 & 0.042 & 0.024 \\
\hline & 0.8 & 1.4 & 0.4 & 0.2 & 0.4 & 0 & 0.012 & 0.013 & 0.010 & ----- & ----- \\
\hline & 0.8 & 1.2 & 0.8 & 0.2 & 0.4 & 0 . & 0.014 & 0.029 & 0.040 & 0.048 & 0019 \\
\hline & 1.0 & 1.0 & 0.4 & 0.2 & 0.4 & 0 & 0.011 & ----- & ----- & ----- & ----- \\
\hline & 1.0 & 1.0 & 0.6 & 0.2 & 0.4 & 0.2 & ---- & 0.017 & ----- & ----- & ----- \\
\hline & 1.0 & 1.2 & 0.4 & 0.2 & 0.4 & 0.2 & 0.011 & ----- & 0.013 & ----- & ----- \\
\hline & 1.0 & 1.2 & 0.6 & 0.2 & 0.4 & 0.2 & 0.016 & 0.033 & 0.061 & 0.045 & 0.024 \\
\hline & 1.0 & 1.2 & 0.8 & 0.2 & 0.4 & 0.2 & 0.014 & 0.016 & 0.013 & ----- & ----- \\
\hline & 1.0 & 1.4 & 0.4 & 0.2 & 0.4 & 0.2 & 0.010 & ----- & ----- & ----- & |---- \\
\hline \multicolumn{7}{|c|}{ Percentage of cases with the break at $\mathrm{T} / 4-2$} & 0.017 & 0.005 & 0.003 & 0.002 & 0.000 \\
\hline \multicolumn{7}{|c|}{ Percentage of cases with the break at T/4 - 1} & 0.013 & 0.005 & 0.003 & 0.005 & 0.001 \\
\hline \multicolumn{7}{|c|}{ Percentage of cases with the break at $\mathrm{T} / 4$} & 0.750 & 0.878 & 0.983 & 0.992 & 0.998 \\
\hline \multicolumn{7}{|c|}{ Percentage of cases with the break at $\mathrm{T} / 4+1$} & 0.013 & 0.007 & 0.004 & 0.001 & 0.001 \\
\hline \multicolumn{7}{|c|}{ Percentage of cases with the break at $\mathrm{T} / 4+2$} & 0.007 & 0.0067 & 0.004 & 0.000 & 0.000 \\
\hline
\end{tabular}




\begin{tabular}{|c|c|c|c|c|c|c|c|c|c|c|c|}
\hline \multicolumn{12}{|c|}{ TABLE 3} \\
\hline \multicolumn{12}{|c|}{ 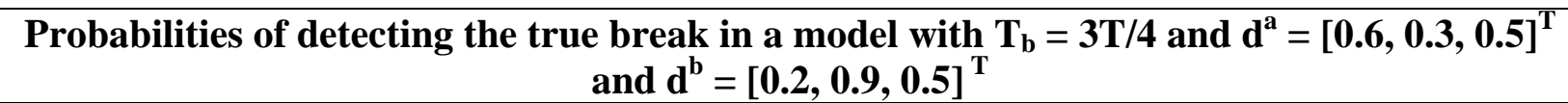 } \\
\hline \multicolumn{4}{|c|}{ First subsample } & \multicolumn{3}{|c|}{ Second subsample } & \multicolumn{5}{|c|}{ Sample size } \\
\hline & $\mathrm{d}_{1}$ & $\mathrm{~d}_{2}$ & $\mathrm{~d}_{3}$ & $\mathrm{D}_{1}$ & $\mathrm{~d}_{2}$ & $\mathrm{~d}_{3}$ & 100 & 200 & 300 & 500 & 1000 \\
\hline $3 \mathrm{~T} / 4-2$ & 0.6 & 0.3 & 0.5 & 0.2 & 0.9 & 0.5 & $\begin{array}{ll}---- \\
\end{array}$ & $\begin{array}{ll}---- \\
--1\end{array}$ & 0.016 & 0.030 & 0.031 \\
\hline $3 \mathrm{~T} / 4-1$ & 0.6 & 0.3 & 0.5 & 0.2 & 0.9 & 0.5 & ----- & ----- & 0.023 & 0.033 & 0.056 \\
\hline \multirow{22}{*}{$3 \mathrm{~T} / 4$} & 0.4 & 0.1 & 0.4 & 0.2 & 0.9 & 0.5 & $\begin{array}{ll}---- \\
\end{array}$ & 0.014 & 0.012 & ----- & ----- \\
\hline & 0.6 & 0.3 & 0.5 & 0.0 & 0.7 & 0.3 & 0.010 & ----- & ----- & ----- & ----- \\
\hline & 0.6 & 0.3 & 0.5 & 0.0 & 0.7 & 0.5 & 0.017 & 0.022 & 0.013 & ------ & ----- \\
\hline & 0.6 & 0.3 & 0.5 & 0.0 & 0.9 & 0.3 & 0.015 & 0.050 & 0.041 & 0.050 & 0.019 \\
\hline & 0.6 & 0.3 & 0.5 & 0.0 & 0.9 & 0.5 & 0.012 & 0.012 & 0.010 & ----- & ----- \\
\hline & 0.6 & 0.3 & 0.5 & 0.0 & 1.1 & 0.3 & ----- & 0.014 & 0.012 & ----- & ----- \\
\hline & 0.6 & 0.3 & 0.5 & 0.0 & 1.1 & 0.7 & ----- & 0.016 & ----- & ----- & ----- \\
\hline & 0.6 & 0.3 & 0.5 & 0.2 & 0.7 & 0.5 & 0.010 & 0.040 & 0.56 & 0.040 & 0.020 \\
\hline & 0.6 & 0.3 & 0.5 & 0.2 & 0.7 & 0.7 & ----- & 0.017 & & ----- & 0.021 \\
\hline & 0.6 & 0.3 & 0.5 & 0.2 & 0.9 & 0.3 & 0.011 & 0.036 & 0.058 & 0.046 & ----- \\
\hline & 0.6 & 0.3 & 0.5 & 0.2 & 0.9 & 0.5 & 0.019 & 0.100 & 0.202 & 0.522 & 0.759 \\
\hline & 0.6 & 0.3 & 0.5 & 0.2 & 0.9 & 0.7 & ----- & 0.026 & 0.036 & 0.050 & 0.012 \\
\hline & 0.6 & 0.3 & 0.5 & 0.2 & 1.1 & 0.3 & 0.011 & 0.012 & 0.015 & ----- & ----- \\
\hline & 0.6 & 0.3 & 0.5 & 0.2 & 1.1 & 0.5 & 0.010 & 0.031 & 0.037 & 0.045 & 0.013 \\
\hline & 0.6 & 0.3 & 0.5 & 0.2 & 1.1 & 0.7 & ----- & ----- & 0.010 & ----- & ----- \\
\hline & 0.6 & 0.3 & 0.5 & 0.4 & 0.9 & 0.3 & 0.010 & ----- & 0.013 & ----- & ----- \\
\hline & 0.6 & 0.3 & 0.5 & 0.4 & 0.9 & 0.5 & (---- & 0.032 & 0.028 & $\begin{array}{l}---- \\
\end{array}$ & 0.023 \\
\hline & 0.6 & 0.3 & 0.5 & 0.4 & 0.9 & 0.7 & $\begin{array}{l}---- \\
\end{array}$ & 0.011 & ----- & ----- & ----- \\
\hline & 0.6 & 0.3 & 0.5 & 0.4 & 0.9 & 0.7 & ----- & ----- & 0.034 & ----- & $\begin{array}{l}---- \\
\end{array}$ \\
\hline & 0.6 & 0.3 & 0.5 & 0.4 & 1.1 & 0.3 & ----- & ----- & 0.013 & ----- & $\begin{array}{l}----- \\
-\end{array}$ \\
\hline & 0.6 & 0.3 & 0.7 & 0.2 & 0.9 & 0.5 & ----- & 0.013 & ----- & ------ & $\begin{array}{l}---- \\
--\end{array}$ \\
\hline & 0.8 & 0.3 & 0.5 & 0.2 & 0.9 & 0.5 & ----- & 0.010 & ----- & ----- & ----- \\
\hline \multirow{2}{*}{$3 \mathrm{~T} / 4+1$} & 0.6 & 0.3 & 0.5 & 0.2 & 0.7 & 0.5 & $\begin{array}{ll}---- \\
\end{array}$ & ----- & 0.011 & $\begin{array}{c}---- \\
\end{array}$ & $\begin{array}{ll}----- \\
\end{array}$ \\
\hline & 0.6 & 0.3 & 0.5 & 0.2 & 0.9 & 0.5 & $\begin{array}{ll}---- \\
\end{array}$ & 0.017 & 0.022 & 0.037 & 0.059 \\
\hline $3 \mathrm{~T} / 4+2$ & 0.6 & 0.3 & 0.5 & 0.2 & 0.9 & 0.5 & ----- & ----- & 0.011 & 0.024 & $\begin{array}{ll}---- \\
\end{array}$ \\
\hline \multicolumn{7}{|c|}{ Percentage of cases with the break at 3T/4 - 2} & 0.074 & 0.061 & 0.053 & 0.032 & 0.037 \\
\hline \multicolumn{7}{|c|}{ Percentage of cases with the break at 3T/4 - 1} & 0.108 & 0.084 & 0.084 & 0.044 & 0.071 \\
\hline \multicolumn{7}{|c|}{ Percentage of cases with the break at $3 \mathrm{~T} / 4$} & 0.654 & 0.715 & 0.730 & 0.864 & 0.871 \\
\hline \multicolumn{7}{|c|}{ Percentage of cases with the break at $3 \mathrm{~T} / 4+1$} & 0.093 & 0.085 & 0.076 & 0.034 & 0.065 \\
\hline \multicolumn{7}{|c|}{ Percentage of cases with the break at $3 \mathrm{~T} / 4+2$} & 0.069 & 0.055 & 0.057 & 0.016 & 0.056 \\
\hline
\end{tabular}




\section{TABLE 4}

Probabilities of detecting the true break date in a model with $T_{b}=T / 2$ and $d^{a}=[0.2,0.4$, $0.3]^{\mathrm{T}}$ and $d^{\mathrm{b}}=[0.6,0.9,1.4]^{\mathrm{T}}$ and a VAR(1) structure for the d-differenced process

\begin{tabular}{|c|c|c|c|c|c|c|c|c|c|c|c|}
\hline \multicolumn{4}{|c|}{ First subsample } & \multicolumn{3}{|c|}{ Second subsample } & \multicolumn{5}{|c|}{ Sample size } \\
\hline $\mathrm{T} / 2$ & $\mathrm{~d}_{1}$ & $\mathrm{~d}_{2}$ & $\mathrm{~d}_{3}$ & $\mathrm{~d}_{1}$ & $\mathrm{~d}_{2}$ & $\mathrm{~d}_{3}$ & 100 & 200 & 300 & 500 & 1000 \\
\hline $\mathrm{T} / 2-1$ & 0.2 & 0.4 & 0.3 & 0.6 & 0.9 & 1.4 & ----- & ----- & 0.010 & 0.023 & 0.052 \\
\hline \multirow{28}{*}{$\mathrm{T} / 2$} & 0.0 & 0.2 & 0.1 & 0.4 & 0.7 & 1.2 & 0.024 & 0.012 & ----- & ----- & ----- \\
\hline & 0.0 & 0.2 & 0.1 & 0.4 & 0.7 & 1.4 & 0.015 & ----- & ----- & ----- & ----- \\
\hline & 0.0 & 0.2 & 0.1 & 0.6 & 0.7 & 1.2 & 0.016 & ---- & ---- & ----- & ----- \\
\hline & 0.0 & 0.2 & 0.1 & 0.6 & 0.9 & 1.4 & 0.011 & 0.035 & 0.026 & 0.020 & ----- \\
\hline & 0.0 & 0.2 & 0.3 & 0.4 & 0.7 & 1.2 & 0.012 & 0.012 & 0.010 & ----- & ----- \\
\hline & 0.0 & 0.2 & 0.3 & 0.4 & 0.7 & 1.4 & ----- & 0.011 & ----- & ----- & ----- \\
\hline & 0.0 & 0.2 & 0.3 & 0.6 & 0.9 & 1.4 & ----- & 0.018 & 0.026 & 0.018 & ----- \\
\hline & 0.0 & 0.4 & 0.1 & 0.6 & 0.7 & 1.2 & 0.010 & ---- & ----- & ----- & ----- \\
\hline & 0.0 & 0.4 & 0.1 & 0.6 & 0.9 & 1.4 & ----- & 0.017 & 0.023 & 0.013 & ----- \\
\hline & 0.0 & 0.4 & 0.3 & 0.4 & 0.7 & 1.2 & 0.013 & 0.017 & ----- & ----- & ----- \\
\hline & 0.0 & 0.4 & 0.3 & 0.6 & 0.9 & 1.4 & ----- & 0.029 & 0.032 & 0.047 & ----- \\
\hline & 0.2 & 0.2 & 0.1 & 0.6 & 0.9 & 1.4 & ----- & 0.011 & 0.011 & 0.011 & ----- \\
\hline & 0.2 & 0.2 & 0.3 & 0.4 & 0.7 & 1.2 & 0.014 & 0.013 & ----- & ----- & ----- \\
\hline & 0.2 & 0.2 & 0.3 & 0.4 & 0.7 & 1.4 & 0.012 & ----- & ----- & ----- & ----- \\
\hline & 0.2 & 0.2 & 0.3 & 0.6 & 0.9 & 1.4 & 0.010 & 0.038 & 0.057 & 0.089 & 0.044 \\
\hline & 0.2 & 0.4 & 0.1 & 0.6 & 0.9 & 1.4 & ----- & 0.014 & ----- & 0.010 & ----- \\
\hline & 0.2 & 0.4 & 0.3 & 0.4 & 0.7 & 1.2 & ----- & 0.014 & 0.032 & 0.027 & ----- \\
\hline & 0.2 & 0.4 & 0.3 & 0.4 & 0.7 & 1.4 & ---- & 0.012 & 0.016 & 0.012 & ----- \\
\hline & 0.2 & 0.4 & 0.3 & 0.6 & 0.7 & 1.2 & ----- & ----- & 0.015 & ----- & ----- \\
\hline & 0.2 & 0.4 & 0.3 & 0.6 & 0.9 & 1.4 & ----- & 0.052 & 0.161 & 0.422 & 0.757 \\
\hline & 0.2 & 0.4 & 0.3 & 0.6 & 0.9 & 1.6 & ----- & ----- & 0.011 & ----- & ----- \\
\hline & 0.2 & 0.4 & 0.3 & 0.8 & 1.1 & 1.6 & ----- & ----- & ----- & 0.013 & ----- \\
\hline & 0.2 & 0.4 & 0.5 & 0.6 & 0.9 & 1.4 & ----- & ----- & 0.011 & 0.019 & ----- \\
\hline & 0.2 & 0.6 & 0.3 & 0.4 & 0.7 & 1.2 & ----- & 0.011 & ----- & ----- & ----- \\
\hline & 0.2 & 0.6 & 0.3 & 0.6 & 0.9 & 1.4 & ----- & 0.025 & 0.042 & 0.052 & 0.018 \\
\hline & 0.4 & 0.4 & 0.3 & 0.6 & 0.9 & 1.4 & ----- & ----- & 0.021 & 0.015 & ----- \\
\hline & 0.4 & 0.4 & 0.5 & 0.6 & 0.9 & 1.4 & ----- & ----- & 0.015 & ----- & ----- \\
\hline & 0.4 & 0.6 & 0.3 & 0.6 & 0.9 & 1.4 & ----- & ----- & 0.015 & ----- & ----- \\
\hline $\mathrm{T} / 2+1$ & 0.2 & 0.4 & 0.3 & 0.6 & 0.9 & 1.4 & ----- & ----- & 0.010 & 0.017 & 0.031 \\
\hline $\mathrm{T} / 2+2$ & 0.2 & 0.4 & 0.3 & 0.6 & 0.9 & 1.4 & ----- & ----- & |---- & $\begin{array}{l}---- \\
\end{array}$ & 0.025 \\
\hline \multicolumn{7}{|c|}{ Percentage of cases with the break at $\mathrm{T} / 2-2$} & 0.032 & 0.012 & 0.015 & 0.016 & 0.012 \\
\hline \multicolumn{7}{|c|}{ Percentage of cases with the break at $\mathrm{T} / 2-1$} & 0.068 & 0.046 & 0.061 & 0.046 & 0.060 \\
\hline \multicolumn{7}{|c|}{ Percentage of cases with the break at $\mathrm{T} / 2$} & 0.448 & 0.582 & 0.658 & 0.879 & 0.865 \\
\hline \multicolumn{7}{|c|}{ Percentage of cases with the break at $\mathrm{T} / 2+1$} & 0.037 & 0.042 & 0.043 & 0.042 & 0.038 \\
\hline \multicolumn{7}{|c|}{ Percentage of cases with the break at $\mathrm{T} / 2+2$} & 0.015 & 0.018 & 0.023 & 0.020 & 0.026 \\
\hline
\end{tabular}




\begin{tabular}{|c|c|c|c|c|c|c|}
\hline \multicolumn{7}{|c|}{ TABLE 5} \\
\hline \multicolumn{7}{|c|}{ Estimated model using white noise disturbances. The US case } \\
\hline \multicolumn{3}{|c|}{ First subsample } & \multirow{2}{*}{ Break date } & \multicolumn{3}{|c|}{ Second subsample } \\
\hline $\mathrm{d}_{1}$ & $\mathrm{~d}_{2}$ & $d_{3}$ & & $\mathrm{~d}_{1}$ & $\mathrm{~d}_{2}$ & $\mathrm{~d}_{3}$ \\
\hline $\begin{array}{c}1.01 \\
(0.84,1.32)\end{array}$ & $\begin{array}{c}1.00 \\
(0.81,1.26)\end{array}$ & $\begin{array}{c}1.00 \\
(0.80,1.30)\end{array}$ & 1974Q4 & $\begin{array}{c}1.50 \\
(1.21,1.72)\end{array}$ & $\begin{array}{c}1.45 \\
(1.14,1.65)\end{array}$ & $\begin{array}{c}1.52 \\
(1.19,1.77)\end{array}$ \\
\hline
\end{tabular}

$d_{1}$ is the order of integration of employment; $d_{2}$ is the order of integration of CPI, and $d_{3}$ is the order of integration of GDP.

\begin{tabular}{|c|c|c|c|c|c|c|}
\hline \multicolumn{7}{|c|}{ TABLE 6} \\
\hline \multicolumn{7}{|c|}{ Estimated model using VAR(1) disturbances. The US case } \\
\hline \multicolumn{3}{|c|}{ First subsample } & \multirow{2}{*}{ Break date } & \multicolumn{3}{|c|}{ Second subsample } \\
\hline $\mathrm{d}_{1}$ & $\mathrm{~d}_{2}$ & $\mathrm{~d}_{3}$ & & $\mathrm{~d}_{1}$ & $\mathrm{~d}_{2}$ & $\mathrm{~d}_{3}$ \\
\hline $\begin{array}{c}0.02 \\
(-0.31,0.43)\end{array}$ & $\begin{array}{c}0.00 \\
(-0.37,0.55)\end{array}$ & $\begin{array}{c}0.00 \\
(-0.22,0.51)\end{array}$ & 1974Q4 & $\begin{array}{c}0.66 \\
(0.44,0.98)\end{array}$ & $\begin{array}{c}0.25 \\
(-0.11,0.43)\end{array}$ & $\begin{array}{c}0.43 \\
(0.11,0.69)\end{array}$ \\
\hline \multicolumn{3}{|c|}{ VAR(1) coefficients } & & \multicolumn{3}{|c|}{ VAR(1) coefficients } \\
\hline$\left(\begin{array}{l}0.90 \\
0.372 \\
0.102\end{array}\right.$ & $\begin{array}{r}-0.025 \\
0.968 \\
-0.071\end{array}$ & $\left.\begin{array}{c}0.032 \\
0.067 \\
.008\end{array}\right)$ & & $\begin{array}{r}0.52 \\
-0.22 \\
-0.0\end{array}$ & $\begin{array}{rr}4 & -0.063 \\
4 & 0.806 \\
9 & -0.043\end{array}$ & $\left.\begin{array}{l}0.125 \\
0.288 \\
1.065\end{array}\right)$ \\
\hline
\end{tabular}




\begin{tabular}{|c|c|c|c|c|c|c|}
\hline \multicolumn{7}{|c|}{ TABLE 7} \\
\hline \multicolumn{7}{|c|}{ Estimated model using white noise disturbances. The Mexican case } \\
\hline \multicolumn{3}{|c|}{ First subsample } & \multirow{2}{*}{ Break date } & \multicolumn{3}{|c|}{ Second subsample } \\
\hline $\mathrm{d}_{1}$ & $\mathrm{~d}_{2}$ & $d_{3}$ & & $\mathrm{~d}_{1}$ & $\mathrm{~d}_{2}$ & $\mathrm{~d}_{3}$ \\
\hline $\begin{array}{c}1.06 \\
(0.90,1.21)\end{array}$ & $\begin{array}{c}0.97 \\
(0.88,1.16)\end{array}$ & $\begin{array}{c}0.99 \\
(0.78,1.23)\end{array}$ & 1959 & $\begin{array}{c}1.52 \\
(1.30,1.81)\end{array}$ & $\begin{array}{c}1.77 \\
(1.37,1.98)\end{array}$ & $\begin{array}{c}1.37 \\
(1.03,1.54)\end{array}$ \\
\hline
\end{tabular}

\begin{tabular}{|c|c|c|c|c|c|c|}
\hline \multicolumn{7}{|c|}{ TABLE 8} \\
\hline \multicolumn{7}{|c|}{ Estimated model using VAR(1) disturbances. The Mexican case } \\
\hline \multicolumn{3}{|c|}{ First subsample } & \multirow{2}{*}{ Break date } & \multicolumn{3}{|c|}{ Second subsample } \\
\hline $\mathrm{d}_{1}$ & $\mathrm{~d}_{2}$ & $\mathrm{~d}_{3}$ & & $\mathrm{~d}_{1}$ & $\mathrm{~d}_{2}$ & $\mathrm{~d}_{3}$ \\
\hline $\begin{array}{c}0.13 \\
(-0.32,0.39)\end{array}$ & $\begin{array}{c}0.03 \\
(-0.31,0.27)\end{array}$ & $\begin{array}{c}0.00 \\
(-0.41,0.37)\end{array}$ & 1962 & $\begin{array}{c}1.20 \\
(0.98,1.34)\end{array}$ & $\begin{array}{c}1.15 \\
(0.92,1.44)\end{array}$ & $\begin{array}{c}1.18 \\
(0.99,1.40)\end{array}$ \\
\hline \multicolumn{3}{|c|}{ VAR(1) coefficients } & & \multicolumn{3}{|c|}{ VAR(1) coefficients } \\
\hline 0.91 & $4-0.046$ & $0.099)$ & & 0.477 & 0.024 & $-0.101)$ \\
\hline-0.40 & $8 \quad 0.781$ & 0.485 & & 6.176 & 0.620 & -1.876 \\
\hline 0.57 & $7-0.025$ & 0.827 & & 0.452 & 0.025 & -0.080 \\
\hline
\end{tabular}


